\title{
Survival of Listeria Monocytogenes in Tomato Juice at 5 and $30^{\circ} \mathrm{C}$ Storage
}

\author{
IOANNIS DIAKOGIANNIS ${ }^{1 *}$, CHARALAMPOS PROESTOS ${ }^{1}$, \\ THEODOROS VARZAKAS ${ }^{2}$ and PANAGIOTA MARKAKI ${ }^{1}$
}

\author{
'Department of Chemistry, University of Athens, \\ Panepistimioupolis Zografou, Athens, Greece, 15784 \\ ${ }^{2}$ Tei Peloponnese, Dept. of Food Technology, School of Agricultural \\ Technology, Food Technology and Nutrition, Kalamata, Greece, 24100
}

http://dx.doi.org/10.12944/CRNFSJ.5.1.01

(Received: January 26, 2017; Accepted: February 01, 2017)

\begin{abstract}
Listeria monocytogenes is a food-borne pathogen and has been associated with a variety of food products including fruits and vegetables, which are important for a healthy human diet. $L$. monocytogenes survives and grows at low temperatures and thus it can be multiplied to dangerous levels in a product which is kept at refrigeration temperatures. This work examines the ability of $L$. monocytogenes to survive, in a product of high consumption frequency, such as tomato juice, in correlation to storage temperature. The results indicate that a significant number of cells survived in tomato juice whether the storage temperature was $30^{\circ} \mathrm{C}$ or $5^{\circ} \mathrm{C}$, although the refrigerator temperature slightly reduces the survival of $L$. monocytogenes cells. An understanding of the cold stress response of the pathogen will be helpful in the design of effective methods to control L. monocytogenes in freezing foods in order to provide consumers with a safe product.
\end{abstract}

Keywords: Listeria monocytogenes; tomato juice;

refrigeration; vegetables; food safety

\section{INTRODUCTION}

Fresh or minimally processed vegetables and fruits are an important part of a healthy human diet rich in vitamins, fibers and nutrients. However, it should be considered that they are also very important as causative agents for several food-borne illnesses. The fresh vegetables and fruit juices can be contaminated with pathogenic microorganisms during growing, harvesting, postharvest handling, processing or post-pasteurization contamination of the product. Outbreaks of human infections, correlated with the consumption of raw fruits and vegetables, have been increased during the past decades $^{1-3}$. The pathogen Listeria monocytogenes is a Gram-positive acapsular, asporogenous, facultatively anaerobic bacterium and is regarded as one of the leading causes of food-borne outbreaks with high fatality rates (listeriosis) ${ }^{1,4}$. The pathogen has been associated with a variety of food products, including dairy foods, meat, poultry, seafood, as well as fruits and vegetables ${ }^{1,5-7}$.

L. monocytogenes can survive in multiple environmental conditions used in food industry such as low temperature, acidic $\mathrm{pH}$, presence of disinfectants, osmotic pressure ${ }^{8-11}$. In a food processing plant, this bacterial pathogen can experience refrigeration temperatures, leading to cold adaptation, which may enhance its survival in vegetable products, and thus the organism can be multiplied to dangerous levels when the product is kept at refrigeration temperatures ${ }^{11-13}$. Changing food habits of the consumer, with a trend towards 
consumption of minimally processed ready-to-eat convenience foods and refrigerated or frozen food products have affected the incidence of listeriosis over the past years ${ }^{5}$. Since refrigeration is one of the most common ways to increase the shelf life of foods, understanding the survival and growth of $L$. monocytogenes at low temperature could provide information to help develop more effective control methods. This study was therefore undertaken to examine the ability of $L$. monocytogenes to survive, in a product of high consumption frequency, such as tomato (Solanum lycopersicum L.) juice, in correlation to storage temperature.

\section{MATERIALS AND METHODS}

\section{Preparation of tomato juice}

Fresh tomatoes (Solanum lycopersicum L.) were purchased from a local market (Athens, Greece). Prior to experimental studies, the tomatoes were washed with tap water for 2 min, follows with distilled water, and dried with absorbent paper at room temperature. The tomatoes were cut into pieces and the stems were removed using a common kitchen knife, before they were transferred into a household blender (Izzy E450 Multi Plus) and converted to juice. The juice was then batchpasteurized at $65^{\circ} \mathrm{C}$ for $30 \mathrm{~min}$ in a water bath (Memmert WNB7-45, Schwawbach, Germany) and was cooled rapidly at room temperature.

\section{Culture preparation and inoculation processing of tomato juice}

An avirulent strain Listeria monocytogenes, DP-L1044 (D. Portnoy, University of Pennsylvania) prepared by a transposon insertion ${ }^{14}$ in the parent strain (Lm10403S), was grown in Brain Heart Infusion broth (BHI, BD, Franklin Lakes, NJ, USA) at $30^{\circ} \mathrm{C}$ for $24 \mathrm{~h}$. A $10 \mathrm{~mL}$ aliquot of the above inoculum was transferred into $1 \mathrm{~L}$ of $\mathrm{BHI}$ broth, which was then incubated at $30^{\circ} \mathrm{C}$; another $10 \mathrm{~mL}$ aliquot was used to inoculate $1 \mathrm{~L}$ of $\mathrm{BHI}$ broth, which was then incubated at $5^{\circ} \mathrm{C}$. The growth of $L$. monocytogenes for each incubation temperature was determined by measuring absorbance (OD) at $600 \mathrm{~nm}$ over time.

Aliquots ( $1 \mathrm{~mL}$ ) of L. monocytogenes culture grown at $30^{\circ} \mathrm{C}$ until early stationary phase $\left(\mathrm{OD}_{600 \mathrm{~nm}}\right.$ $=0.850$ ), were serially decimally diluted to attain the desired inoculum level for tomato juice samples.
Each inoculum was added to each sample to yield a final concentration of $5.0 \times 10^{5} \mathrm{CFU} \mathrm{g}^{-1}$ tomato juice (5.70 log CFU g ${ }^{-1}$ ).

\section{Storage experiments}

Two sets of tomato juice samples were utilized, the first for storage at $30^{\circ} \mathrm{C}$ and the second for storage at $5^{\circ} \mathrm{C}$. The first set of 8 samples (storage at $30^{\circ} \mathrm{C}$ ) was enumerated at $1,3,5$ and 7 days and this procedure was repeated ( $n=2,2 \times 4$ samples). The second set of 8 samples (storage at $5^{\circ} \mathrm{C}$ ) was enumerated at 2, 4, 8 and 12 days and also was repeated ( $n=2,2 \times 4$ samples).

Uninoculated blank samples were also stored under the same conditions and analyzed with the same method for the presence of the pathogen and no cells were found.

\section{Enumeration of Listeria monocytogenes}

Samples of tomato juice $(25 \mathrm{~g})$ were aseptically transferred and homogenized with 225 $\mathrm{mL}$ sterile Buffered Peptone Water (code CM0509, Oxoid LTD, Basingstoke, Hampshire, United Kingdom) in stomacher bags (stomacher 400, Light Interscience, Rockland, MA). Appropriate serial decimal dilutions were made in Buffered Peptone Water. L. monocytogenes was counted by surfaceplating $0.1 \mathrm{~mL}$ of appropriate serial dilutions of the homogenate on PALCAM Agar Base plates (code CM0877, Oxoid LTD, Basingstoke, Hampshire, United Kingdom). The Petri dishes were incubated at $30^{\circ} \mathrm{C}$ for 48

\section{Statistical analysis}

All the above experiments were carried out in duplicated. Student's t-test was used to determine statistical significance at a confidence level of $95 \%$.

The results on the enumeration of $L$. monocytogenes in tomato juice inoculated at $5 \times 10^{5}$ CFU g"1 (5.7 log g"1) are shown in Fig. 1. In tomato juice stored at $30^{\circ} \mathrm{C}, L$. monocytogenes viable cells counts reduced slightly but with no significant difference during the first day ( 0.55 log CFU g"1 lower than the initial inoculated sample). The population of the bacteria stabilized over the next 6 days and remained at $5.14 \pm 0.11 \log$ CFU g"1 during the seventh day of storage. 
The cells of $L$. monocytogenes were reduced significantly $(1.31 \log$ decline, $\mathrm{P}<0.05)$ compared to the initial population after 2 days storage in tomato juice stored at refrigeration temperature $\left(5^{\circ} \mathrm{C}\right)$. In the next 10 days storage period, the number of the cells remained constant and was $4.05 \pm 0.05 \log$ CFU g"1 after 12 days of storage. The refrigeration temperature reduces the survival of L. monocytogenes cells ( $1 \log$ CFU g"1) compared to $30^{\circ} \mathrm{C}$ storage temperature, however, in both cases the population remained constant at each storage temperature.

A significant number of $L$. monocytogenes cells had the ability to overcome the acidic nature of the tomato juice and survived in the product whether the storage temperature was $30^{\circ} \mathrm{C}$ or $5^{\circ} \mathrm{C}$. $L$. monocytogenes has the ability to survive and grow at low temperatures and thus the organism can multiply to dangerous levels when the product is kept at refrigeration temperatures. Modification of membrane lipid composition is clearly an important adaptation mechanism in L. monocytogenes, which allows it to grow in a stressful environment such as low temperature ${ }^{15,16}$. Changes in lipid composition can lead to changes in cytoplasmic membrane permeability and fluidity, which may in turn contribute to tolerance ${ }^{11,17}$.
Previous studies observed that $L$. monocytogenes is able to survive in tomatoes ${ }^{18-}$ ${ }^{20}$ and in vegetables and fruits such as lettuce ${ }^{21}$, cabbage $^{22}$, vegetable broth ${ }^{23}$, bell pepper ${ }^{24}$, leafy endives $^{25}$, apple ${ }^{26}$, pear and melon ${ }^{27}$ at different temperatures.

Data regarding the behavior of $L$. monocytogenes in tomato juice during freezing storage are limited. Our findings support that $L$. monocytogenes has the ability to survive in tomato juice regardless of freezing storage or not, although when the storage temperature is $5^{\circ} \mathrm{C}$ the survival potential of the bacteria is lower than the storage temperature of $30^{\circ} \mathrm{C}$.

Understanding response mechanisms of cold adaptation will improve the strategies, which will help to manipulate the survival and growth of $L$. monocytogenes in freezing foods, and exert microbial control at these points. Although, pasteurization of the product is adequate to control small amounts of the bacterium, L. monocytogenes is able to attach to and survive on surfaces found in food processing plants, forming biofilms and post-pasteurization contamination of the product is possible ${ }^{13}$. However due to the specific abilities of this pathogen to overcome the processing hurdles, its control remains a challenge. Compliance with

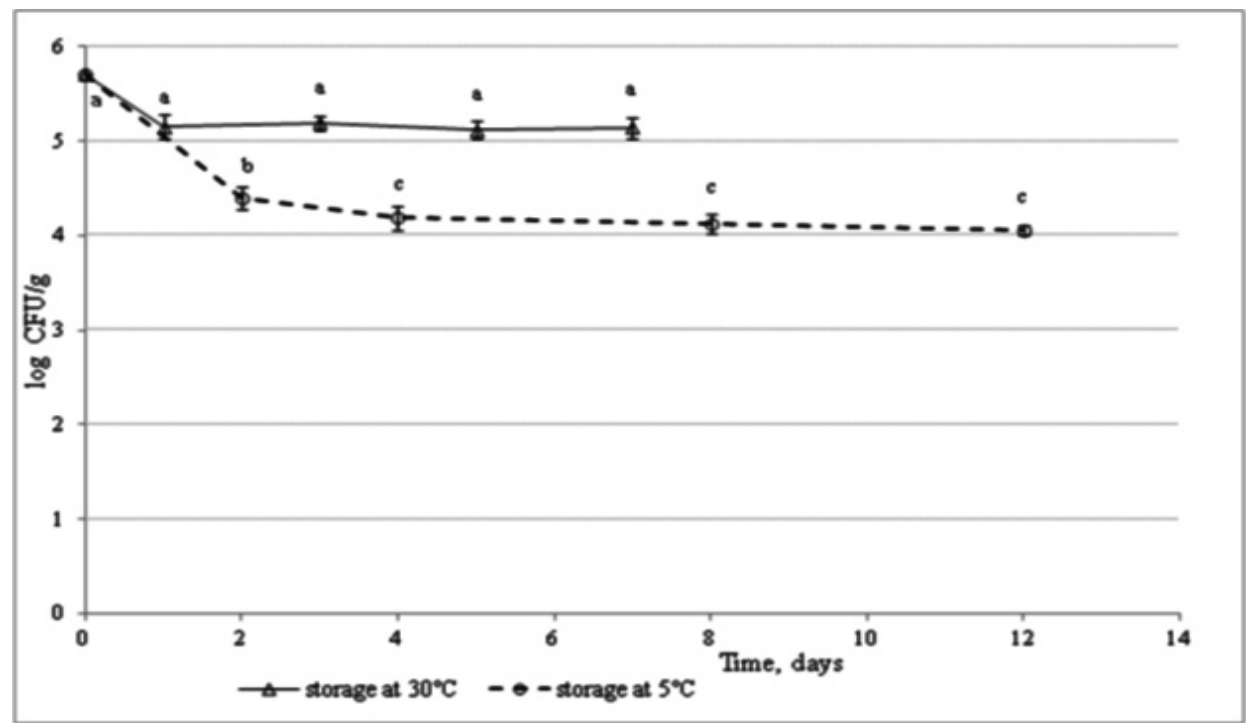

Fig. 1: Listeria monocytogenes population in tomato juice stored at $30^{\circ} \mathrm{C}$ ( triangles) or at $5^{\circ} \mathrm{C}$ (circles). Values with different superscript letters indicate statistically significant differences $(P<0.05)$. 
the Good Manufacturing Practices, implementation of Hazard Analysis Critical Control Points (HACCP) and the surveillance of the pathogen in the processing environment are crucial in order to provide consumers with a safe product ${ }^{28}$.

\section{ACKNOWLEDGEMENT}

The Authors Acknowledge Financial Help from National and Kapodistrian University of Athens, Special Accounts.

\section{REFERENCES}

1. Farber J.M., Peterkin P.I. Listeria monocytogenes. In: Lund, B.M., Baird-Parker, A.C., Gould, G.W. (Eds.). The Microbiological Safety and Quality of Food. Aspen Publishers Inc. Gaithersburg, MD. 1178-1232: (2000)

2. Berger C.N., Sodha S.V., Shaw R.K., Griffin P.M., Pink D., Hand P., Frankel G. Fresh fruit and vegetables as vehicles for the transmission of human pathogens. Environmental Microbiology; 12(9): 23852397: (2010)

3. Karabiyikli P., Deðirmenci H., Karapinar M. Inhibitory effect of sour orange (Citrus aurantium) juice on Salmonella typhimurium and Listeria monocytogenes. LWT - Food Science and Technology; 55: 421-425: (2014)

4. Najjar M.Z.B., Chikindas M., Montville T.J. Changes in Listeria monocytogenes membrane fluidity in response to temperature stress. Applied and Environmental Microbiology; 73(20): 6429-6435: (2009)

5. Gandhi M., Chikindas M.L. Listeria: A foodborne pathogen that knows how to survive. International Journal of Food Microbiology; 113: 1-15 (2007)

6. Berberi A., Dimareli P., Diakogiannis I., Markaki P., Mastronicolis S.K. "Memorized" modifications on Listeria monocytogenes' membrane lipids and fatty acid profile after its survival on soft white feta-type cheese. Annals of Microbiology; 66: 1099-1108 (2016)

7. Denis N., Zhang H., Leroux A., Trudel R., Bietlot $\mathrm{H}$. Prevalence and trends of bacterial contamination in fresh fruits and vegetables sold at retail in Canada. Food Control; 67: 225-234: (2016)

8. Mastronicolis S.K., Arvanitis N., Karaliota A., Magiatis P., Heropoulos G., Litos C., Moustaka H., Tsakirakis A., Paramera
A., Papastavrou P. Coordinated regulation of cold-induced changes in fatty acids with cardiolipin and phosphatidylglycerol composition among phospholipid species for the food pathogen Listeria monocytogenes. Applied and Environmental Microbiology; 74: 4543-4549: (2008)

9. Bisbiroulas P., Psylou M., Iliopoulou I., Diakogiannis I., Berberi A., Mastronicolis S.K. Adaptational changes in cellular phospholipids and fatty acid composition of the food pathogen Listeria monocytogenes as a stress response to disinfectant sanitizer benzalkonium chloride. Letters in Applied Microbiology, 52: 275-280: (2011)

10. Giotis E.S., McDowell D.A., Blair I.S., Wilkinson B.J. Role of branched chain fatty acid in $\mathrm{pH}$ stress tolerance in Listeria monocytogenes. Applied and Environmental Microbiology; 73: 997-1001: (2007)

11. Beales, N. Adaptation of microorganisms to cold temperatures, weak acid preservatives, low $\mathrm{pH}$, and osmotic stress: A review. Comprehensive Reviews in Food Science and Food Safety, 3: 1-20: (2004)

12. Julotok M., Singh A.K., Gatto C., Wilkinson B.J. Influence of fatty acid precursors, including food preservatives, on the growth and fatty acid composition of Listeria monocytogenes at 37 and $10^{\circ} \mathrm{C}$. Applied and Environmental Microbiology, 76: 1423-1432: (2010)

13. Mastronicolis S.K., Diakogiannis I., Berberi A., Bisbiroulas P., Soukoulis C., Tzia, C. Effect of cold adaptation on the survival of Listeria monocytogenes in ice-cream formulations during long-term frozen storage. Annals of Microbiology, 61: 931-937: (2011)

14. Camilli A., Goldfine H., Portnoy D.A. Listeria monocytogenes mutants lacking phosphatidylinositol-specific phospholipase $\mathrm{C}$ are avirulent. Journal of Experimental 
Medicine; 173(3): 751-754: (1991)

15. Annous B.A., Becker L.A., Bayles D.O., Labeda, D.P., Wilkinson B.J. Critical role of anteiso- $\mathrm{C}_{15: 0}$ fatty acid in the growth of Listeria monocytogenes at low temperatures. Applied and Environmental Microbiology; 63: 38873894: (1997)

16. Mastronicolis S.K., Boura A., Karaliota A., Magiatis P., Arvanitis N., Litos C., Tsakirakis A., Paraskevas P., Moustaka H, Heropoulos G. Effect of cold temperature on the composition of different lipid classes of the foodborne pathogen Listeria monocytogenes: Focus on neutral lipids. Food Microbiology; 23:184-194: (2006)

17. Diakogiannis I., Berberi A., Siapi E., ArkoudiVafea A., Giannopoulou L., Mastronicolis S.K. Growth and membrane fluidity of food-borne pathogen Listeriamonocytogenes in the presence of weak acid preservatives and hydrochloric acid. Frontiers in Microbiology/ Microbial Physiology and Metabolism; 4 (Article 152): 1-6: (2013)

18. Beuchat L.R., Brackett R.E. Behavior of Listeria monocytogenes inoculated into raw tomatoes and processed tomato products. Applied and Environmental Microbiology; 57(5): 1367-1371: (1991)

19. Oladunjoye A.O., Singh S., ljabadeniyi O.A. Inactivation of Listeria monocytogenes ATCC 7644 on fresh-cut tomato using nisin in combinations with organic salts. Brazilian Journal of Microbiology; 47: 757763: (2016)

20. Poimenidou S.V., Chatzithoma D-N., Nychas G-J., Skandamis P.N. Adaptive response of Listeria monocytogenes to heat, salinity and low $\mathrm{pH}$, after habituation on cherry tomatoes and lettuce leaves. PLoS One; 11(10): 1-16: (2016)

21. Samara A., Koutsoumanis K.P. Effect of treating lettuce surfaces with acidulants on the behavior of Listeria monocytogenes during storage at 5 and $20^{\circ} \mathrm{C}$ and subsequent exposure to simulated gastric fluid.
International Journal of Food Microbiology; 129: 1-7: (2009)

22. Yoon J-H., Bae Y-M., Jung S-Y, Cha M-H., Ryu K., Park K-H., Lee S-Y. Predictive modeling for the growth of Listeria monocytogenes and Salmonella Typhimurium on fresh-cut cabbage at various temperatures. Journal of Korean Society for Applied Biological Chemistry; 57(5): 631-638: (2014)

23. de Mederios Barbosa I., da Costa Medeiros J.A., de Oliveira K.Á.R., Gomes-Neto N.J., Tavares J.F., Magnani M., de Souza E.L. Efficacy of the combined application of oregano and rosemary essential oils for the control of Escherichia coli, Listeria monocytogenes and Salmonella Enteritidis in leafy vegetables. Food Control; 59: 468-477: (2016)

24. Alwi N.A., Ali A. Reduction of Escherichia coli 0157, Listeria monocytogenes and Salmonella enterica sv. Typhimurium populations on fresh-cut bell pepper using gaseous ozone. Food Control; 46: 304-311: (2014)

25. Carlin F., Nguyen-the C., da Silva A.A. Factors affecting the growth of Listeria monocytogenes on minimally processed fresh endive. Journal of Applied Bacteriology; 78(6): 636-646: (1995)

26. Salazar J.K., Carstens C.K., Bathija V.M., Narula S.S., Parish M., Tortorello M.L. Fate of Listeria monocytogenes in fresh apples and caramel apples. Journal of Food Protection; 79(5): 696-702: (2016)

27. Colás-Medà P., Abadias M., Oliveira M., Usall J., Viñas I. Influence of fruit matrix and storage temperature on the survival of Listeria monocytogenes in a gastrointestinal simulation. Food Control; 73: 1045-1052: (2017)

28. Melo J., Andrew P.W., Faleiro M.L. Listeria monocytogenes in cheese and the dairy environment remains a food safety challenge: The role of stress responses. Food Research International; 67: 75-90: (2015) 